\title{
Ultrasound membrane hybrid processes for dairy wastewater treatment: pilot-scale analysis
}

\section{Szabolcs Kertész, Ildikó Kovács, Cecilia Hodúr, Gábor Keszthelyi-Szabó, Gábor Veréb \& Zsuzsanna László}

To cite this article: Szabolcs Kertész, Ildikó Kovács, Cecilia Hodúr, Gábor Keszthelyi-Szabó, Gábor Veréb \& Zsuzsanna László (2016): Ultrasound membrane hybrid processes for dairy wastewater treatment: pilot-scale analysis, Desalination and Water Treatment, DOI: 10.1080/19443994.2016.1173386

To link to this article: http://dx.doi.org/10.1080/19443994.2016.1173386

册Published online: 18 Apr 2016.

Submit your article to this journal 지

Q View related articles $\sqsubset$

View Crossmark data $\nearrow$ 


\title{
Ultrasound membrane hybrid processes for dairy wastewater treatment: pilot-scale analysis
}

\section{Szabolcs Kertész*, Ildikó Kovács, Cecilia Hodúr, Gábor Keszthelyi-Szabó, Gábor Veréb, Zsuzsanna László}

Faculty of Engineering, Department of Process Engineering, University of Szeged, Moszkvai krt. 9., H-6725 Szeged, Hungary, Tel. +36 62546582; Fax: +36 62546549; email: kertesz@mk.u-szeged.hu (Sz. Kertész)

Received 20 April 2015; Accepted 16 March 2016

\begin{abstract}
Novel wastewater treatments are necessary to effectively decrease the organic load of dairy wastewater before disposal. In this work the feasibility of a hybrid process of membrane filtration combined with ultrasonication to decrease organic load was investigated. The efficiency of the advanced hybrid process that simultaneously applies ultrasonic irradiation and pressure-driven membrane ultrafiltration was examined. Polyethersulfone ultrafiltration membranes with 20 and $50 \mathrm{kDa}$ molecular weight cut-off were tested. The effects of the continuous and half intermittent ultrasonic irradiation during the ultrafiltration were compared. Ultrafiltration fluxes, chemical oxygen demand retentions and membrane, pore fouling and polarization layer resistances were analyzed in a combined process. Furthermore, mass transfer coefficients, fouling coefficients and concentrations on membrane surface were also calculated and compared. The results showed that the best correlation were achieved by plotting the cake filtration model, but the other models also have given relatively good correlations using gradual pore blocking and intermediate filtration models. For this reason the membrane filtration ultrasonication should be further investigated for future applications.
\end{abstract}

Keywords: Dairy wastewater; Half intermittent and continuous ultrasonication; Ultrafiltration hybrid processes; Fouling resistances

\section{Introduction}

Membrane separations have been extensively used in dairy industry for selective separation of different molecules and compounds. In these membrane processes, the pressure difference is the driving force between the two sides of the membrane; therefore, they are called pressure-driven membrane processes or membrane separation technologies. However, these widely used industrial applications have a main obstacle, namely the membrane fouling. Fouling phenomena during the UF process is the retained particle accumulation on the membrane surface causing significant reduction in the separation efficiencies [1]. Ultrasound has been used to improve the permeate flux and recovery of membrane permeability and to reduce

\footnotetext{
${ }^{*}$ Corresponding author.
}

Presented at EuroMed 2015: Desalination for Clean Water and Energy Palermo, Italy, 10-14 May 2015. Organized by the European Desalination Society. 
the rapid flux decline caused by concentration polarization and membrane fouling [2,3].

Over the last decade, various studies have been conducted using ultrasound as a means of mitigating membrane fouling, in ultrafiltration process, and to improve fouled membrane cleaning [4,5]. Ultrasonication (US) treatment has been comprehensively accepted as a powerful method for fouled membrane cleaning in water- and wastewater treatment. US has been regarded as an efficient technique in membrane filtration and fouled membrane cleaning to enhance the permeate flux and membrane permeability recovery [6]. US refers to sound wave propagation into a medium beyond the audible frequency range above $20 \mathrm{kHz}$ or 20,000 cycles per second. For US, surface cleaning generally uses a frequency in the range of $16-70 \mathrm{kHz}$ [7]. US creates a number of physical forces, which can be generated by the alternating compression and rarefaction cycles, like vibration and physical agitation. In addition to the acoustic cavitation microjets, shear, shockwaves, and acoustic streaming are also initiated [8]. Different mechanisms may lead to particle detachment from a particle-fouled membrane surface, including cavitation mechanisms (microstreaming and microstreamers), acoustic streaming (Fig. 1), and micro-jets.

Acoustic vortex microstreaming, henceforward acoustic streaming, on the membrane surface are proven to contribute to the cleaning of the membrane surface [9]. Acoustic streaming is defined as the absorption of acoustic energy resulting in fluid flow, which does not require the collapse of cavitation bubbles [10]. Acoustic streaming in the liquid increases the velocity of the solute and results in eddy currents near the membrane surface [11]. Therefore, this mechanism causes liquid bulk movement toward and away from the membrane surface. It may loosen, break, and disperse the fouling polarization or cake layer, furthermore scour loosely attached particles

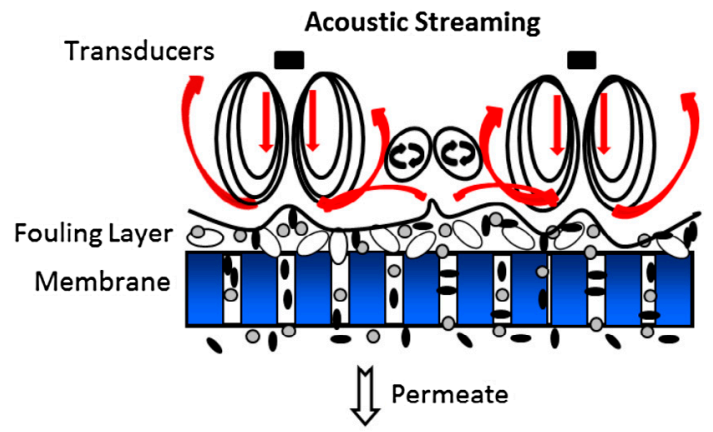

Fig. 1. Main mechanism for particle detachment during ultrasonic membrane filtration. from the membrane surface and prevents further deposition. Since the cross-flow velocities in cross-flow filtration is much higher than the feed flow in deadend filtration, the acoustic streaming effect can be more efficient in dead-end filtration [12].

Dairy industry requires huge volumes of water and generates wastewater and has wide fluctuationsin their effluent quality [13]. In dairy industry technology, water is used throughout a lot of steps generating large volumes of effluents, mainly white waters and it has high biochemical oxygen demand and chemical oxygen demand (COD) contents with high levels of dissolved or suspended solids including fats, oils, and grease, nutrients such as ammonia or minerals and phosphates, milk components like lactose and proteins, and cleaning chemicals, detergents $[14,15]$. This type of effluents may result in water eutrophication due to the presence of nitrogen and phosphorus when it is discarded without treatment [16,17]. For the mentioned reasons, treating dairy effluents is one of the most crucial tasks not only for the environment, but also for water recycling.

In this work, the feasibility of a hybrid process of membrane filtration combined with ultrasonication for dairy model wastewater treatment was investigated. The efficiency of the advanced hybrid process that simultaneously applies ultrasonic irradiation and pressure-driven membrane ultrafiltration was examined. The effects of the continuous and half intermittent ultrasonic irradiation during the ultrafiltration were compared.

\section{Materials and methods}

\subsection{Ultrasonically assisted ultrafiltration experiments}

The experimental equipment and apparatuses are shown schematically in Fig. 2. The UF experiments without ultrasonication (no US) were carried out in

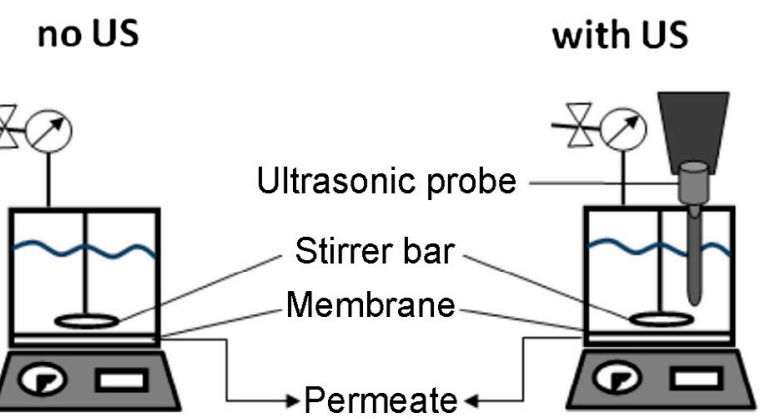

Fig. 2. Experimental setup configurations. 
batch solvent resistant stirred cell (Millipore, Model 8400). The UF experiments with ultrasonication (with US) were carried out in a very similar setup, which also consisted of the same batch solvent resistant stirred cell (Millipore, Model 8400) fitted with an ultrasonic probe. The head of this probe was an ultrasonic processor UP100H (Hielscher Ultrasonics $\mathrm{GmbH}$, Germany). The maximal power of the ultrasonic apparatus is $100 \mathrm{~W}$, it was operated at $30 \mathrm{kHz} .100 \%$ amplitude and one cycle ultrasonic irradiation was set in continuous US operation mode and $100 \%$ amplitude and half cycle ultrasonic irradiation $(0.65-0.65 \mathrm{~s}$ on-off modes) for half intermittent US irradiation. In our previously reported work, 20 and 30\% amplitude were also tested in continuous mode for separation of whey solution using regenerated cellulose ultrafiltration membranes [18].

UF flat sheet membranes of polyethersulfone with 20 and $50 \mathrm{kDa}$ molecular weight cut-off (MWCO) and membrane effective area of $0.004 \mathrm{~m}^{2}$ were used (Ultura, Italy). Before conducting the UF experiments, the membrane was immersed into the aqueous solution for one night in order to reach equilibrium. The applied transmembrane pressure (TMP) of $0.1 \mathrm{MPa}$ was constant and achieved by inert nitrogen gas. All measurements were carried out at constant $50^{\circ} \mathrm{C}$, as this is an average temperature value for the homogenized dairy wastewaters produced in the industry. The average temperatures at both input (feed) and output of the filtration cell (permeate and retentate) were measured $50 \pm 1^{\circ} \mathrm{C}$. The initial feed volume was $100 \mathrm{~cm}^{3}$. The UF experiments were carried out until $50 \mathrm{~cm}^{3}$ of the total sample was filtered. The model dairy wastewater in the feed tank was always agitated, in no US mode, using a magnetic stirrer to provide an efficient mixing of $300 \mathrm{rpm}$, assured a homogeneous solution without excessive vortex formation. In the ultrasonically mixed cell, an equivalent Reynolds number was calculated by measuring the equivalent stirring velocity, resulting the same fluxes as in the stirred batch cell (see Section 2.4). All of the UF experiments were repeated three times to calculate an accurate average. The composition of the feed, retentate and permeate were quantified by different methods. The organic content was measured by COD tests. COD was determined in test tubes (Lovibond, Germany) with an ET 108 digester and a PC CheckIt photometer (Lovibond, Germany). The permeate and concentrate turbidity was determined with a $\mathrm{HACH}$ 2100AN turbidimeter (Hach, USA). The conductivity and $\mathrm{pH}$ were measured with a multi-parameter analyzer (Consort C535, Belgium). Model dairy wastewater was prepared from skimmed milk powder $\left(5 \mathrm{~g} \mathrm{dm}^{-3}\right)$ (Szekszárd, Tolnatej Zrt., Hungary) and the anionic surfactant cleaning agent Chemipur CL80 (Nagycserkesz, Hungaro Chemicals, Hungary) at a concentration of $0.5 \mathrm{~g} \mathrm{dm}^{-3}$. The model dairy wastewater characteristics: $5,750 \pm 30 \mathrm{mg} \mathrm{L}^{-1}$ of COD, 390 $\pm 45 \mathrm{NTU}$ of turbidity, $7.4 \pm 0.1$ of $\mathrm{pH}$, and 0.91 $\pm 0.05 \mathrm{mS} \mathrm{cm}^{-1}$ of conductivity.

\subsection{Calculation methods}

Fouling is evaluated with a relationship between relative flux $\left(J_{\text {rel }}\right)$ which is the ratio of the flux at any given time $\left(\mathrm{L} \mathrm{m}^{-2} \mathrm{~h}^{-1}\right)$ during the fouling test to the distilled water flux of the clean membrane $\left(\mathrm{L} \mathrm{m}^{-2} \mathrm{~h}^{-1}\right)$ :

$J_{\text {rel }}=\frac{J}{J_{\mathrm{W}}} \quad(-)$

The total resistance $\left(R_{\mathrm{T}}\right)$ is composed of three resistances:

$R_{\mathrm{T}}=R_{\mathrm{M}}+R_{\mathrm{F}}+R_{\mathrm{P}} \quad\left(\mathrm{m}^{-1}\right)$

where $R_{\mathrm{M}}$ is the membrane, $R_{\mathrm{F}}$ is the pore fouling resistance, and $R_{P}$ is the polarization layer resistance. $R_{\mathrm{M}}$ was calculated as:

$R_{\mathrm{M}}=\frac{\Delta p}{J_{\mathrm{W}} \eta_{\mathrm{W}}} \quad\left(\mathrm{m}^{-1}\right)$

where $J_{W}$ is the water flux of clear membrane $\left(\mathrm{L} \mathrm{m}^{-2} \mathrm{~h}^{-1}\right)$, and $\eta_{\mathrm{W}}$ is the viscosity of water at $50^{\circ} \mathrm{C}$ (Pa s). $R_{\mathrm{F}}$ can be measured via the pure water flux $\left(J_{\mathrm{W} 2}\right)$, after washing off the polarization layer from the membrane. $R_{\mathrm{F}}$ and $R_{\mathrm{P}}$ can be calculated as:

$$
\begin{aligned}
& R_{\mathrm{F}}=\frac{\Delta p}{J_{\mathrm{W} 2} \eta_{\mathrm{W}}}-R_{\mathrm{M}} \quad\left(\mathrm{m}^{-1}\right) \\
& R_{\mathrm{P}}=\frac{\Delta p}{J_{\mathrm{C}} \eta_{\mathrm{WW}}}-R_{\mathrm{M}}-R_{\mathrm{F}} \quad\left(\mathrm{m}^{-1}\right)
\end{aligned}
$$

where $\eta_{\mathrm{Ww}}$ is the viscosity of the wastewater at $50^{\circ} \mathrm{C}$ (Pa s), $J_{C}$ is the constant flux at the end of the concentration $\left(\mathrm{L} \mathrm{m}^{-2} \mathrm{~h}^{-1}\right)$. The selectivity of a membrane for a given solute was expressed by the average (apparent) retention:

$R=\left(1-\frac{c}{c_{0}}\right) \times 100(\%)$

where $c$ is the average concentration of the solute in the permeate phase, and $c_{0}$ is the concentration of the solute in the bulk solution (for COD: $\left(\mathrm{mg} \mathrm{L}^{-1}\right)$ ). 


\subsection{Determination of diffusion coefficients}

Diffusion coefficients were determined at $50^{\circ} \mathrm{C}$ with an Armfield CERb apparatus (Armfield, Great Britain) [19]. A specially designed diffusion cell is mounted on top of the stirred vessel and clamped into the desired position using the locking screw. The equipment consists of a variable speed magnetic stirrer and stirring bar for agitation of the test solution. The diffusion apparatus uses vertical capillaries $5 \mathrm{~mm}$ long with a diameter of $1 \mathrm{~mm}$, which restricts the diffusion to one dimension. The concentration at the lower ends is assumed constant and the concentration at the top ends is effectively zero during the experiment. The diffusion coefficient was determined on the basis if Fick's law by Eqs. (7) and (8), as it was discussed in our earlier study [18]:

$$
\begin{aligned}
& \frac{V}{C_{\mathrm{M}}} \frac{\mathrm{d} k}{\mathrm{~d} t}=-D \frac{d^{2} \pi}{4} N \frac{c_{0}}{x} \\
& D=-\frac{4 V x}{d^{2} \pi N c_{0} C_{\mathrm{M}}} \frac{\mathrm{d} k}{\mathrm{~d} t}
\end{aligned}
$$

where $V$ is volume of water in outer vessel in liters (L), $x$ is the length of capillaries $(\mathrm{cm}), d$ is the diameter of capillaries $(\mathrm{cm}), N$ is the number of capillaries $(N=121), c_{0}$ is the concentration of the dairy wastewater $\left(\mathrm{g} \mathrm{dm}^{-3}\right), C_{\mathrm{M}}$ is the turbidity change for unit concentration change (NTU), $\mathrm{d} k / \mathrm{d} t$ is the rate of change of turbidity with time (NTU s${ }^{-1}$ ). Measurements were carried out with $5.5 \mathrm{~g} \mathrm{dm}^{-3}$ model dairy wastewater, by measuring the change of turbidity and conductivity in distilled water. The measurements were triplicated, the diffusion coefficient at $50^{\circ} \mathrm{C}$ was found to be $1.902 \times 10^{-10} \pm 5.94 \times 10^{-12} \mathrm{~m}^{2} \mathrm{~s}^{-1}$.

\subsection{Theory}

\subsubsection{Determination of $C M C$}

Critical micelle concentration experiments were carried out by adding different amounts of $55 \mathrm{~g} \mathrm{dm}^{-3}$ model dairy wastewater in distilled water and measuring the conductivity. The temperature was kept at $50 \pm 1{ }^{\circ} \mathrm{C}$ using a heatable magnetic stirrer. The conductivity was measured with a multi-parameter analyser (Consort C535, Belgium).

\subsubsection{Determination of Reynolds numbers}

Since the Reynolds number cannot be used in the ultrasonically mixed cell, equivalent Reynolds numbers were calculated [20] by measuring the equivalent stirring velocity, resulting in the same fluxes as in the mixed ultrafiltration batch cell. In these ultrasonication cases, the characteristic radius was the radius of the membrane. It was found that the effect of half intermittent ultrasonication and continuous ultrasonication mixing are the same as stirring with $n=716$ and 1,458 and 1,223 and $1,296 \mathrm{~min}^{-1} \mathrm{rev}$ in the case of 20 and $50 \mathrm{kDa}$ membranes, respectively.

\subsubsection{Determination of mass transfer coefficients and concentrations on membrane surface}

Cake filtration, intermediate filtration, standard pore blocking, and complete pore blocking are commonly used models to describe the fouling mechanisms in membrane filtrations [21-23]. These filtration laws are summarized in Table 1.

In Eqs. (12)-(19), $J$ is the flux, $J_{0}$ is the initial flux, the various $k$ are the fouling coefficients. The various $K$ terms are the mass transfer coefficients for the associated filtration laws. In a stirred batch cell, the solute mass transfer coefficient can be calculated from the following correlations [23]:

$K_{\mathrm{c}}=0.0443 \frac{D}{b} R e^{0.75} S c^{0.33} \quad$ if $R e>3200$

where $R e=\frac{\omega b^{2} \rho}{\eta}, S c=\frac{\eta}{\rho D}, b$ is the stirring radius, $\omega$ is the stirring velocity ( $\mathrm{rad} \mathrm{s}^{-1}$ ) and $D$ is the diffusion coefficient $\left(\mathrm{m}^{2} \mathrm{~s}^{-1}\right)$.

With the assumption of a convection-diffusion mechanism during filtration, the flux is generally expressed by a simplified equation [24]:

$J=K_{\mathrm{c}} \ln \left(\frac{c_{\mathrm{M}}-c_{\mathrm{P}}}{c_{\mathrm{F}}-c_{\mathrm{P}}}\right)$

where $c_{M}$ is the concentration on the membrane surface, $c_{P}$ is the permeate concentration, and $c_{F}$ is the feed concentration. The polarization layer concentration was calculated according to the following equation:

$c_{\mathrm{M}}=\left(c_{\mathrm{F}}-c_{\mathrm{P}}\right) e^{\frac{I_{\mathrm{c}}}{K_{\mathrm{c}}}}+c_{\mathrm{P}}$

\section{Results and discussion}

\subsection{The determination of CMC of model wastewater}

The critical micellar concentration (CMC) of model wastewater was estimated by measuring the 
Table 1

Filtration laws [21-23]

\begin{tabular}{|c|c|c|c|c|}
\hline \multirow{2}{*}{$\frac{\text { Fouling mechanism }}{\text { Complete pore blocking }}$} & \multicolumn{2}{|l|}{ Filtration law } & \multicolumn{2}{|c|}{ Constant pressure filtration $J_{0} A=$ const } \\
\hline & $J=J_{0} e^{-k_{\mathrm{b}} t}$ & $(12)$ & $\ln J=\ln J_{0}-k_{\mathrm{b}} t$ & $(16)$ \\
\hline $\begin{array}{l}\text { Gradual pore blocking } \\
\text { (standard pore blocking) }\end{array}$ & $J=J_{0}\left(1+\frac{1}{2} K_{\mathrm{S}}\left(A J_{0}\right)^{0.5} t\right)^{-2}$ & $(13)$ & $\frac{1}{\sqrt{J}}=\frac{1}{\sqrt{J_{0}}}+k_{\mathrm{s}} t \quad k_{\mathrm{s}}=0.5 K_{\mathrm{s}} A^{0.5}$ & $(17)$ \\
\hline Intermediate filtration & $J=J_{0}\left(1+K_{\mathrm{i}} A J_{0} t\right)^{-1}$ & $(14)$ & $\frac{1}{J}=\frac{1}{J_{0}}+k_{\mathrm{i}} t \quad k_{\mathrm{i}}=K_{\mathrm{i}} A$ & $(18)$ \\
\hline Cake filtration & $J=J_{0}\left(1+2 K_{\mathrm{c}}\left(A J_{0}\right)^{2} t\right)^{-0.5}$ & $(15)$ & $\frac{1}{J^{2}}=\frac{1}{J_{0}^{2}}+k_{\mathrm{c}} \quad k_{\mathrm{c}}=2 K_{\mathrm{c}} A^{2}$ & $(19)$ \\
\hline
\end{tabular}

conductivity of the solution at $50{ }^{\circ} \mathrm{C}$ (Fig. 3). Since the presence of milk powder affects the experimental value of CMC of the detergent, the conductivity was measured dropping a mixed wastewater solution (using an extreme high concentration of $55 \mathrm{~g} \mathrm{dm}^{-1}$ model wastewater). The CMC value of the model wastewater was obtained at $22.38 \mathrm{~g} \mathrm{dm}^{-3}$ at $50^{\circ} \mathrm{C}$ as shown in Fig. 3.

\subsection{The ultrafiltration fluxes}

During our UF experiments, the ultrasonication from the feed side was used as described in the materials and methods, since Kyllönen et al. found that this kind of configuration is more effective in ultrafiltration, than the irradiation from the permeate side [25].

In the ultrafiltration experiments model dairy wastewater was tested. The ultrafiltration membrane fluxes without ultrasonication, (no US, Fig. 4), ultrafiltration with continuous ultrasonication (with continuous US), and with half intermittent ultrasonication (with half intermittent US) were primarily studied. Studies were carried out with 20 and $50 \mathrm{kDa} \mathrm{MWCO}$ PES membranes and the relative fluxes $\left(J_{\text {rel }}\right.$ : calculated with Eq. (1)) are shown in Fig. 4. The highest average flux was observed with continuous ultrasonication. It is generally accepted that the US increases the flux primarily by changing the polarization layer and decreasing the solute concentration at the membrane surface [26]. It is interesting to note that the flux increasing effect of ultrasonication was more pronounced using $50 \mathrm{kDa}$ membrane.

The linearized filtration laws (Eqs. (16)-(19)) were plotted against measured data (Fig. 4). It was found that the best correlations were achieved by plotting the cake filtration model, but the other models the gradual pore blocking and intermediate filtration models also have given relatively good correlations

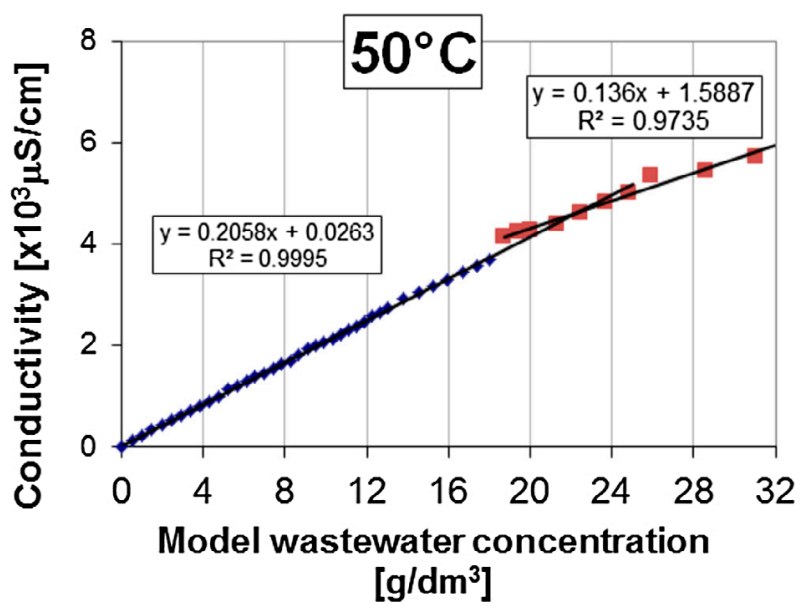

Fig. 3. Determination of CMC by conductivity measurements at $50^{\circ} \mathrm{C}$.

using Eqs. (13) and (14); $R^{2}$ varies between 0.90 and 0.98. It suggests that the ultrafiltration of model dairy wastewater is not squarely gel layer controlled, the real mechanisms is probably more complex. Based on Eqs. (9)-(19), the mass transfer coefficients and the fluxes of the cake filtration model were calculated. As Fig. 4(a) and (b) show, the simulated flux data are in a good correlation with the measured data. The mass transfer coefficients in the mixed cell increased with ultrasonication and a higher $K_{c}$ value was observed with continuous ultrasonication (Table 2). The fouling coefficient, $k_{\mathrm{c}}$ decreased with ultrasonication and continuous ultrasonication had the lowest value in case of both membranes. The calculated concentration on the membrane surface $\left(c_{\mathrm{M}}\right)$ increased with ultrasonication. The conductivity retention increased with ultrasonication and half intermittent ultrasonication had the highest value; except of continuous ultrasonication using $50 \mathrm{kDa}$ membrane the concentration at the surface of the membrane reached the $\mathrm{CMC}$ value. 

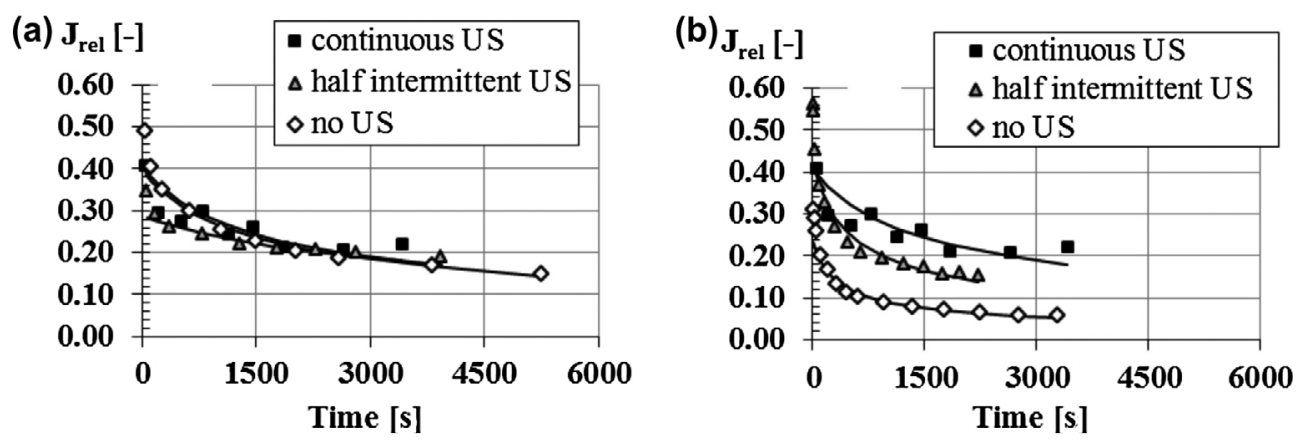

Fig. 4. Ultrafiltration membranes relative fluxes: (a) $20 \mathrm{kDa}$ membrane and (b) $50 \mathrm{kDa}$ membrane; $T=50^{\circ} \mathrm{C}$; $\mathrm{TMP}=0.1 \mathrm{MPa}$ ). Continuous lines represent the fitting results of fouling models.

Table 2

Calculated mass transfer coefficients and fouling coefficients in a stirred or ultrasonically mixed batch cell

\begin{tabular}{llllll}
\hline Membrane (kDa) & Ultrafiltration & $K_{\mathrm{c}}\left(\mathrm{m} \mathrm{s}^{-1}\right)$ & $k_{\mathrm{c}}\left(\mathrm{m}^{4} \mathrm{~L}^{-6} \mathrm{~h}^{-1}\right)$ & $R_{\mathrm{cond}}(\%)$ & $c_{\mathrm{M}}(\mathrm{wt} \%)$ \\
\hline PES20 & Without ultrasonication & $1.48 \times 10^{-5}$ & $1.67 \times 10^{-2}$ & 10.35 \\
& With half intermittent ultrasonication & $2.83 \times 10^{-5}$ & $1.20 \times 10^{-2}$ & 16.53 & 20.33 \\
& With continuous ultrasonication & $4.83 \times 10^{-5}$ & $9.90 \times 10^{-3}$ & 14.48 \\
& & & & 23.47 \\
PES50 & Without ultrasonication & $1.48 \times 10^{-5}$ & $4.95 \times 10^{-3}$ & 3.59 & 20.28 \\
& With half intermittent ultrasonication & $4.23 \times 10^{-5}$ & $1.15 \times 10^{-3}$ & 7.86 & 23.17 \\
& With continuous ultrasonication & $4.42 \times 10^{-5}$ & $5.74 \times 10^{-4}$ & 7.01 & 21.97 \\
\hline
\end{tabular}

\subsection{The ultrafiltration resistances}

The membrane resistances $\left(R_{\mathrm{M}}\right)$, fouling resistances $\left(R_{\mathrm{F}}\right)$, polarization layer resistances $\left(R_{\mathrm{P}}\right)$, and total resistances $\left(R_{\mathrm{T}}\right)$ were calculated using Eqs. (2)-(5). It is obvious from the data in Fig. 5, that with both membrane types the total resistances decreased with ultrasonication and the continuous ultrasonication had more pronounced effects. A comparison of the calculated $R_{\mathrm{T}}$ and the $k_{\mathrm{c}}$ indicated that these parameters decreased with increasing ultrasound intensity. The retention results shown in Fig. 6 support this statement.

From our measurements it was obvious that in the ultrafiltration laboratory stirred cell device the resistances might have a noticable impact on filtration, but the ultrasonication effect can vary the values of $R_{\mathrm{F}}$ and $R_{\mathrm{P}}$ from lot-to-lot. This results also show that (similarly than it was found by plotting filtration models) in case of ultrasonically enhanced ultrafiltration the mechanism of filtration is complex, to find an exact model to describe the flux decline in the function of the time further examinations are necessary.

\subsection{The ultrafiltration retentions}

Fig. 6 shows the COD retentions ( $R_{\mathrm{COD}}$ : calculated with Eq. (6)) of the ultrafiltration experiments without US, with half intermittent US and with continuous US modes. The retentions increased from 53.1 to $65.4 \%$ and to $74.4 \%$ using half intermittent and continuous ultrasonication, respectively. The observed COD rejections were found to be in accordance with the results obtained from $c_{M}$ results (concentration on the membrane surface). The $c_{M}$ values are important to characterize the back diffusion of the accumulated particles on the surface of the membrane which are important in determining the membrane rejections. In Table 2 it was found that the $c_{M}$ values were higher than the CMC value of the model wastewater $\left(22.38 \mathrm{~g} \mathrm{dm}^{-3}\right)$ in the case of both ultrasonication with $20 \mathrm{kDa}$ membrane and half intermittent US with $50 \mathrm{kDa}$. In these cases, the rejections of the COD were also higher than without ultrasonication. These results could be explained in terms of concentration polarization effects, since the formed more dense accumulated layer rejected the particles more efficiently. 
(a)

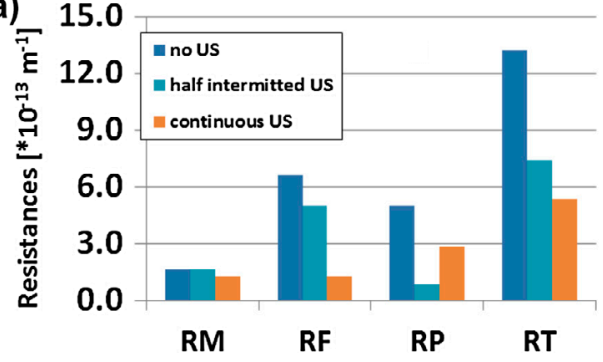

(b)

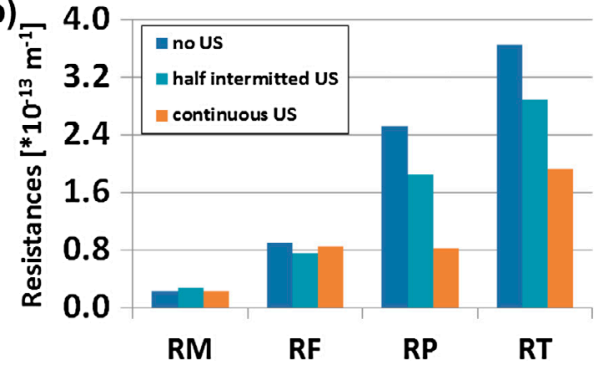

Fig. 5. Filtration resistances during ultrafiltrations: (a) $20 \mathrm{kDa}$ membrane and (b) $50 \mathrm{kDa}$ membrane; $T=50^{\circ} \mathrm{C}$; $\mathrm{TMP}=0.1 \mathrm{MPa} ; R_{\mathrm{M}}$ : membrane resistances; $R_{\mathrm{F}}$ : fouling resistances; $R_{\mathrm{P}}$ : polarization layer resistances.
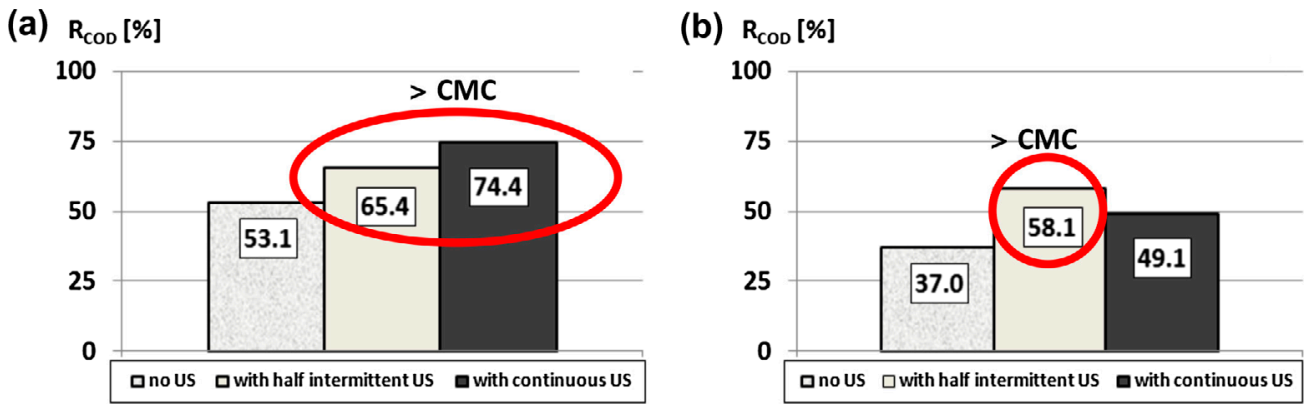

Fig. 6. COD retentions: (a) $20 \mathrm{kDa}$ membrane and (b) $50 \mathrm{kDa}$ membrane; $\mathrm{T}=50^{\circ} \mathrm{C}$; $\mathrm{TMP}=0.1 \mathrm{MPa}$.

\section{Conclusions}

In this study, the feasibility of a hybrid process of membrane filtration combined with ultrasonication for dairy model wastewater treatment was investigated. From filtration law models it was found that the best correlation were achieved by plotting the cake filtration model, but the other models also have given relatively good correlations. It suggests that the ultrafiltration of model dairy wastewater was not squarely gel layer controlled, the real mechanisms is probably more complex.

However, dead-end stirred cell device is commonly used in laboratories to characterize microfiltration and ultrafiltration membranes, ultrasonication efficiency and filtration model classification should be further investigated for future applications in filtration operations. Furthermore, the use of the intermittent mode compared to the continuous mode to apply ultrasound irradiation should be explored in order to minimize energy consumption, with the aim to develop this technology in industrial scale.

\section{Acknowledgments}

This project was supported by the János Bolyai Research Scholarship of the Hungarian Academy of Sciences. The authors are also grateful for the financial support provided by the project Hungarian Science and Research Foundation (OTKA contract number K 105021 and 112096).

\section{References}

[1] S. Muthukumaran, S. Kentish, S. Lalchandani, M. Ashokkumar, R. Mawson, G.W. Stevens, H.M. Kyllönen, P. Pirkonen, M. Nystrom, Membrane filtration enhanced by ultrasound: A review, Desalination 180 (2005) 319-335.

[2] T. Kobayashi, T. Kobayashi, Y. Hosaka, N. Fujii, Ultrasound-enhanced membrane-cleaning processes applied water treatments: Influence of sonic frequency on filtration treatments, Ultrasonics 41 (2003) 185-190.

[3] M. Aliasghari Aghdam, H. Mirsaeedghazi, M. Aboonajmi, M.H. Kianmehr, Effect of ultrasound on different mechanisms of fouling during membrane clarification of pomegranate juice, Bioresour. Technol. 30 (2015) 127-131.

[4] A. Simon, L. Penpenic, N. Gondrexon, S. Taha, G. Dorange, A comparative study between classical stirred and ultrasonically-assisted dead-end ultrafiltration, Ultrason. Sonochem. 7 (2000) 183-186.

[5] M. Cai, S. Zhao, H. Liang, Mechanisms for the enhancement of ultrafiltration and membrane cleaning by different ultrasonic frequencies, Desalination 263 (2010) 133-138.

[6] X. Chai, T. Kobayashi, N. Fujii, Ultrasound-associated cleaning of polymeric membranes for water treatment, Sep. Purif. Technol. 15 (1999) 139-146. 
[7] M.O. Lamminen, H.W. Walker, L.K. Weavers, Cleaning of particle-fouled membranes during cross-flow filtration using an embedded ultrasonic transducer system, J. Membr. Sci. 283 (2006) 225-232.

[8] J. Chandrapala, C. Oliver, S. Kentish, M. Ashokkumar, Ultrasonics in food processing, Ultrason. Sonochem. 19 (2012) 975-983.

[9] M.O. Lamminen, H.W. Walker, L.K. Weavers, Mechanisms and factors influencing the ultrasonic cleaning of particle-fouled ceramic membranes, J. Membr. Sci. 237 (2004) 213-223.

[10] T.G. Leighton, Bubble population phenomena in acoustic cavitation, Ultrason. Sonochem. 2(2) (1995) S123-S136.

[11] T. Tran, S. Gray, B. Bolto, T.D. Farmer, T.F. Collings, Ultrasound enhancement of microfiltration performance for natural organic matter removal, Org. Geochem. 38 (2007) 1091-1096.

[12] H.M. Kyllönen, P. Pirkonen, M. Nyström, Membrane filtration enhanced by ultrasound: A review, Desalination 181 (2005) 319-335.

[13] N. Mirabella, V. Castellani, S. Sala, Current options for the valorization of food manufacturing waste: A review, J. Cleaner Prod. 65 (2014) 28-41.

[14] C. Aydiner, U. Sen, D.Y. Koseoglu-Imer, E.C. Dogan, Hierarchical prioritization of innovative treatment systems for sustainable dairy wastewater management, J. Cleaner Prod. 112 (2016) 4605-4617.

[15] B. Sarkar, P.P. Chakrabarti, A. Vijaykumar, V. Kale, Wastewater treatment in dairy industries-Possibility of reuse, Desalination 195 (2006) 141-152.

[16] M.L. Gerardo, M.P. Zacharof, R.W. Lovitt, Strategies for the recovery of nutrients and metals from anaerobically digested dairy farm sludge using cross-flow microfiltration, Water Res. 47 (2013) 4833-4842.

[17] M. Amini, H. Younesi, A.A.Z. Lorestani, G. Najafpour, Determination of optimum conditions for dairy wastewater treatment in UAASB reactor for removal of nutrients, Bioresour. Technol. 145 (2013) 71-79.

[18] M. Ábel, Zs.L. Kiss, S. Beszédes, C. Hodúr, G. Keszthelyi-Szabó, Zs. László, Ultrasonically assisted ultrafiltration of whey solution, J. Food Process Eng. 38(5) (2015) 467-473.

[19] Armfield Ltd., Diffusion of a Liquid Apparatus: Instruction Manual for Product Code CERB, 9, Armfield Ltd, Ringwood, 2011.

[20] N. Santhanam, N.N. Bakhshi, New experimental technique to measure ultrasonically induced mixing, J. Acoust. Soc. Am. 43(2) (1968) 377-378.

[21] B. Hu, K. Scott, Microfiltration of water in oil emulsions and evaluation of fouling mechanism, Chem. Eng. J. 136 (2008) 210-220.

[22] E. Iritani, N. Katagiri, T. Takenaka, Membrane pore blocking during cake formation in constant pressure and constant flux dead-end microfiltration of very dilute colloids, Chem. Eng. Sci. 122 (2015) 465-473.

[23] S. Banerjee, S. De, An analytical solution of Sherwood number in a stirred continuous cell during steady state ultrafiltration, J. Membr. Sci. 389 (2012) 188-196.

[24] S.R. Jadhav, N. Verma, A. Sharma, P.K. Bhattacharya, Flux and retention analysis during micellar enhanced ultrafiltration for the removal of phenol and aniline, Sep. Purif. Technol. 24 (2001) 541-557.

[25] H. Kyllönen, P. Pirkonen, M. Nyström, J. NuortilaJokinen, A. Grönroos, Experimental aspects of ultrasonically enhanced cross-flow membrane filtration of industrial wastewater, Ultrason. Sonochem. 13 (2006) 295-302.

[26] D. Veerasamy, A. Supurmaniam, Z.M. Nor, Evaluating the use of in-situ ultrasonication to reduce fouling during natural rubber skim latex (waste latex) recovery by ultrafiltration, Desalination 236 (2009) 202-207. 